\title{
Cloning Headless Frogs and Other Important Matters: Conversation Topics and Network Structure*
}

\author{
Peter Bearman, Columbia University \\ PaOlo ParigI, Columbia University
}

\begin{abstract}
This article considers which people talk about important matters, what people talk about when they discuss "important matters," and the implications of conversation topic for the interpretation of results arising from the General Social Survey (GSS) network instrument based on the "important matters" name generator. We show that half the people who report not talking about anything have nothing to talk about, whereas the others have no one to talk to. Secondly, we show that people tend to talk about things that many would regard as unimportant, for example, cloning of headless frogs, eating less red meat, and so on. Given this, the connection between characteristics of discussion networks and achievement of instrumental ends - for example, getting a job or enhancing social support - is tenuous. Finally, we show that there is substantial topicalter dependency. This dependency suggests that many substantive findings reported about, for example, gender differences in network composition might be an artifact of the data-collection instrument. Micro-level topic-alter dependencies reflect macro-level associations between attributes, topics, and roles. Consequently, cross-cultural comparison of GSS network questions is problematic. Solutions for escaping these methodological dilemmas are proposed.
\end{abstract}

Since its introduction in 1985, the General Social Survey (GSS) social network instrument has remained at the center of research into the structure of American discussion networks (Bailey \& Marsden 1999; Ruan 1998; Straits 2000). The GSS

* We have benefited from the advice of Michael Sobel and Hannah Brilckner. Robert Faris assisted with the design of the survey instrument used here. Beverly Wiggins gracefully implemented the many changes to the Carolina Poll that this instrument required. Seed funding from the University of North Carolina is acknowledged. Support from the Institute for Social and Economic Research and Policy is acknowledged. Authorship order is alphabetical. Address all correspondence to Peter Bearman, Institute for Social and Economic Research and Policy, 814 IAB, MC 3355, Columbia University, NY, NY 10027. E-mail: psb17@columbia.edu.

(c) The University of North Carolina Press

Social Forces, December 2004, 83(2):535-557 


\section{6 / Social Forces 83:2, December 2004}

network instrument has been used to describe local network structures, link individual network characteristics to substantive outcomes, for example, getting a job, receiving social support, and accessing opportunities (Campbell \& Lee 1991; Marsden 1987), and relate network position to a variety of broad themes in urban sociology and class analysis (Alex-Assensoh 1997; Ranki \& Quane 2001). The central element of the GSS network instrument is the name generator. In this article, we consider whether one should have confidence in the GSS instrument, similar name generators, and more broadly, many of the substantive conclusions arrived at from analysis of GSS-style network data.

Network instrument name generators do just what they sound like they do; they generate names. The name generator, "who are your enemies?" should generate a different set of names than the generator "who are your friends?" for example. In the GSS, the specific name generator used is "From time to time, most people discuss important matters with other people. Looking back over the last 6 months, who are the people with whom you discussed matters important to you?"' The general assumption of most prior work is that the instrument effectively captures, through the name generator, the important relationships that individuals have with others and that the matters discussed are in some sense important enough to proxy resources available to individuals as they pursue their life goals - for example, forming opinions, finding employment, seeking health care, and the like. The idea is that people talk about important matters with others who are important to them.

Some prior research has considered how people interpret the GSS name generator. Bailey and Marsden (1999), for example, report that while individuals proffer different interpretations of the "important matters" generator, that network composition does not differ in relation to these different subjective interpretive frameworks. Using a different methodology, one less subject to sample selection bias, Straits (2000) reports similar results - wording alterations introduced into the name generator produce just a few insignificant effects. Both conclude, consequently, that although the mechanism linking the name generator to the names generated is ambiguous, the results are robust. Here the claim advanced on behalf of the instrument is that the proof is in the eating of the pudding. ${ }^{2}$

At least for the U.S., it appears to be that the GSS name generator elicits respondent's strong ties. Most people (although not all, by far) can think of someone they talked to about an important matter within the past six months, and in general, the people they identify (by role) make intuitive sense; their spouse, children, parents, close friends, and so on. Because the people they describe are close to them, they tend to know each other and have similar social characteristics. Consequently, these networks are relatively dense and homogeneous. As Marsden summarizes, these core discussion networks tend to be "small, centered on kin, comparatively dense, and homogenous by comparison to the respondent population as an opportunity structure" (Marsden 1987:126-27). Against this background, as indicated above, variation in the structure of these networks is associated with variation in substantive outcomes. Thus, people with exceptionally heterogeneous 
networks, males for example, might be expected to have greater access to information about jobs, but less social support.

It is odd that, in the midst of this work, both on the methodology and the substantive significance of the GSS instrument, that little attention has been paid to what people actually talk about when they talk about important matters. There are two reasons to care. First, work that suggests that the "important matter" network is associated with the achievement of instrumental outcomes (getting a job, securing social support, etc.) presumes either that the important matters discussed are actually important, or that they stand in an equivalence relation to matters that are actually important for the achievement of substantive ends, for example, borrowing money, learning about jobs, and so on. The general assumption is that people talk about matters important to them with people important to them. But if the matters are not really important, it is possible that they talk about them with people who are not really important. Knowing what people talk about would help us understand the significance of the core discussion networks individuals are embedded in.

Second, and more importantly, topics of conversation may be systematically associated with specific roles. While it is possible that the kin-centered networks reported for the U.S. are being generated because of the structure of North America society - which is the basic idea of the research to date, it is also possible that these networks are being generated as an artifact of preferences some individuals have to talk about certain matters with family members (Ruan 1998). If preferences linking topics to roles vary across social settings - which seems to be a reasonable idea in cross-cultural context, for example - knowing what people talk about when they talk about important matters would facilitate substantive interpretation of comparative research findings. Consequently, decoupling alters and topics in ego's conversation flow will further our understanding not only of the functioning of the network instrument but also of ego's structure of relations.

So, what do people actually talk about? Just about everything is the simple answer. And are the topics "important"? Some are important in the sense that they reflect recent events in the news. At the time of our data collection, stories concerned the "nanny" in Boston who murdered her charge, a state trooper who was shot on interstate 95 , road-construction projects, moral issues in the Clinton White House, and trouble in the livestock (specifically pig) industry, and these and other stories were frequently discussed. Some are also important in the sense that they reflect issues of "personal" importance, for example, caring for one's aged parents, deciding on what school to send the kids to, dealing with a difficult boss, getting a loan on a new car, quitting smoking, eating less red meat, losing weight, and so on. And some are important in a global, abstract sense, for example, the "collapse of American moral life," the disappearance of local community, the "desertion of God," and globalization. Finally, some appear to be relatively trivial - for example, getting a new haircut, caring for the neighbor's lawn, or the new traffic lights installed in town. ${ }^{3}$ 
Against this background, the puzzles this article considers are the following. First, if the topics that count as important are so broad as to include the potentially unimportant, why do so many people not report talking about anything with anybody? Is it because they have nothing to talk about, or, as the literature assumes, nobody to talk to? Second, since the topics people talk about are completely heterogeneous in scope and range is there a foundation from which one could actually use the GSS data or any data coming from similar name generators, to describe anything meaningful at all about the core discussion networks of Americans? Third, is there patterning of topics and alters, and if so, what does this patterning suggest about the structure of American society and the possibilities for comparative analysis.

To anticipate the main arguments, we show that roughly one-half of the people who report not talking about anything in the last six months have nothing to talk about, even apparently getting a haircut. The other half may have something to talk about, but have nobody to talk to. We show that it is possible to observe quite striking topic-role patterns, that these patterns are asymmetric, and that they reveal what appear to be deep divisions by gender. Some of the observed asymmetries are not surprising: for example, husbands talk to their friends about their relationships, while wives (try to) talk to their husbands about their relationships. But the roletopic overlap extends across multiple roles beyond spouse and structures the data that we observe. Consequently, one has to be concerned that many of the research results reported earlier, especially those focused on gender differences in ego network structure, are an artifact of previously unobserved role-topic overlaps. Finally, we consider the macro-structure that organizes, beyond these dyadic asymmetries, the topics of conversation that people have in relation to their social characteristics. Not surprisingly, patterning across roles, topics and social strata is acute, although often in unexpected directions. This suggests that inference across diverse cultural contexts using the GSS stratagem is a risky enterprise.

\section{Data and Methods}

The data for our analysis comes from the North Carolina Poll, an annual representative survey of adults residing in North Carolina. ${ }^{4}$ Data used in this article arise from interviews conducted by telephone between November 1 and 12, 1997. The questions of interest for this study are presented below. ${ }^{5}$

Question 1: From time to time, most people discuss important matters with other people. Looking back over the last six months, that is, since early last May, have you discussed important matters with anyone?

Question 2: Thinking back to the most recent discussion you had about an important matter, would you mind telling me, briefly, what was the general topic of this discussion? 
Question 3: Most recently, is the person you talked to about this matter: a spouse, other relative, friend, counselor, lawyer, doctor, acquaintance, or what?

Question 4: Which best describes why you haven't discussed any important matters with others lately. Would you say that: (1) You haven't had any important matters to discuss in the last six months, or (2) You haven't had a person you wanted to discuss important matters with in the last six months.

The second and third questions were asked only to those individuals that reported having discussed important matters in the last six months. The question on the topics of conversation was open-ended; more than four hundred discrete topics were recorded. Question four was asked only to those who reported not talking about anything important in the past six months. Almost $80 \%$ of the sample reported talking about something important in the last six months. We refer to this group as the "talkers." It follows that $20 \%$ of the respondents reported not talking with anyone in the past six months. We refer to them as the "silent."

In order to obtain leverage on the relationship between conversation content and role structure, we aggregated the 400 individual topics into 9 broad content domains. ${ }^{6}$ These domains and the distribution of responses for each domain are presented in Table 1 below. Issues related to household finances and money are the most frequently discussed "important matters."

The third question provided a list of alters. If the respondent selected two alters, the interviewer prompted him or her to choose the person he or she spoke to most recently. In the analyses that follow, we retain for comparability the standard GSS strategy for aggregation of alters, focusing on spouses, friends, other relatives, and acquaintances. Table 2 reports the distribution of alters across categories presented to the respondents.

Throughout we consider a set of standard statistical techniques to investigate patterning of roles and contents, the determinants of talking, and the characteristics of the silent. Since these methods are frequently found in the literature, we do not describe them in detail here. In some instances, we use techniques not as common in the sociological literature. These are described where invoked. Finally, we consider the macro-structure of conversation using multiple correspondence analysis (hereafter, MCA). An exploratory analysis such as MCA is particularly suitable in this case, as the contingency table includes many categories, and the variables are of a categorical nature. We retained only the components with an eigen value (EV) greater than $1 / Q$ where $Q$ represents the number of variables in the analysis (Greenacre 1994). This left us with only two dimensions to analyze. We correct the EV of each dimension following Greenacre (1994). ${ }^{7}$ 


\begin{tabular}{lcc}
\hline Topic domains & Frequency & Percentage \\
\hline Community Issue & 60 & 11.9 \\
News and economy & 33 & 6.5 \\
Kids and education & 50 & 9.9 \\
Politics and election & 57 & 11.3 \\
Life and health & 63 & 12.4 \\
Relationships & 50 & 9.9 \\
Money and house & 80 & 15.8 \\
Ideology and religion & 61 & 12.1 \\
Work & 52 & 10.3 \\
& 506 & 100 \\
\hline
\end{tabular}

\section{Results}

We first consider the simplest problem - who talks - and model the factors associated with talking about important matters. We then consider with whom the talkers' talk, and what they talked about when they did talk. Specifically, we focus on the presence of role-topic dependencies and consider their implication for interpretation of a set of previously published substantive results on gender differences in network composition. We then focus on the silent people, and consider why they report not talking. Finally, we consider patterning across topics and roles at the macro-levels. We consider how the observed role, topic, and attribute patterning in our data limit the inferences one can make about structure of ego-networks in cross-national (or cultural) studies.

\section{Who Talks About Something}

Leaving behind, for the moment, what individuals talked about with others if they talked, we first consider who talked about anything with someone. Substantial work on this topic has been previously reported, and our main concern here is centered on assessing whether or not our data replicate previous findings, through comparison to previously published research. Earlier research has shown that some basic individual characteristics play a role in shaping the structure of ego's network (Marsden 1987; Moore 1990). In this article we consider the most important of these attributes, specifically: gender, race, marital status, employment status, political attitudes, household composition, education, and age. Frequency distributions for selected variables describing the sample of respondents in our data are reported in Table 3.

Individual's ego-networks vary across the life course. Marsden, for example, reports that young and middle-aged individuals have the largest network range (1987:128). Consequently, we expect age to have a negative effect on the likeli- 


\begin{tabular}{lcc}
\hline & Frequency & Percentage \\
\hline & & \\
Alter talked to about important matters & 171 & 28.8 \\
Spouse & 72 & 12.1 \\
Other relative & 228 & 38.4 \\
Friend & 10 & 1.6 \\
Counselor & 8 & 1.5 \\
Lawyer & 9 & 1.5 \\
Doctor & 40 & 6.7 \\
Acquaintance & 55 & 9.2 \\
Other & & \\
& 593 & 100 \\
\hline
\end{tabular}

hood of discussing: older individuals are less likely to report discussing anything important in the last 6 months. Fischer reports (1982) that education is positively associated with likelihood of having discussion partners, consequently we expect to observe similar results here. With respect to employment status, marital status, household composition, and religious affiliation, we expect to observe similar simple mechanisms operating to shape the probability of discussion. Specifically, having a job, being married, having children, and attending religious services should enlarge ego's network and thus increase the chances of having discussed something important in the last six months. Those with a political attitude, whatever its direction, are also expected to be more likely to report discussing something with someone in the last 6 months.

The effect of gender on propensity to discuss is not immediately clear. On the one hand, most network studies suggest that women are embedded in more intense strong-tie networks than men, so one might expect gender to positively affect the probability of having an important discussion topic, presuming that important topics arise from such intense relationships. On the other hand, previous work has suggested that there are significant gender differences in the structure of egonetworks, for example, women tend to form networks with a higher number of kin than men (Moore 1990). But the structure of networks should not influence the probability of discussion unless both men and women thought that some topics (for example, those discussed with weak-ties) were more "important" than others. One idea is that gender differences in network composition may arise from different material situations. Fischer, for example, argues that younger women are more constrained than men in their ability to make social ties beyond kinship; only later in their life cycle do women experience more liberty in enlarging their circle of associates (Fischer 1982:254). A direct assessment of this idea is possible simply by interacting age and gender. Here, we would expect to observe the expression of gender on discussion conditioned by age, such that as women age, 


\section{TABLE 3: Sample Characteristics}

\begin{tabular}{|c|c|c|}
\hline & $\mathrm{N}$ & Percentage \\
\hline \multicolumn{3}{|l|}{ Attributes } \\
\hline \multicolumn{3}{|l|}{ Gender } \\
\hline Males & 325 & 42.4 \\
\hline Females & 442 & 57.6 \\
\hline \multicolumn{3}{|l|}{ Race } \\
\hline White & 617 & 80.7 \\
\hline Nonwhite & 147 & 19.3 \\
\hline \multicolumn{3}{|l|}{ Marital status } \\
\hline Never married & 124 & 16.2 \\
\hline Divorced or widowed & 197 & 25.6 \\
\hline Married & 447 & 58.2 \\
\hline \multicolumn{3}{|l|}{ Having a political opinion } \\
\hline No & 267 & 42.8 \\
\hline Yes & 357 & 57.2 \\
\hline \multicolumn{3}{|c|}{$\begin{array}{l}\text { How many children below } 16 \text { years } \\
\text { of age live with you }\end{array}$} \\
\hline No children & 493 & 63.6 \\
\hline At least 1 & 282 & 36.4 \\
\hline \multicolumn{3}{|l|}{ Education level } \\
\hline Less than high school & 118 & 15.3 \\
\hline High school graduate & 227 & 29.5 \\
\hline At least some college & 425 & 55.2 \\
\hline \multicolumn{3}{|l|}{ Age } \\
\hline 18 to 24 year old & 71 & 9.3 \\
\hline 25 to 44 year old & 318 & 41.5 \\
\hline 45 to 64 year old & 243 & 31.7 \\
\hline Older than 65 & 134 & 17.5 \\
\hline
\end{tabular}

they will be more likely to report discussing something important in the last 6 months. To assess these mechanisms, we fit a logistic model on the likelihood of talking and report results in Table 4. Overall, there are no real surprises, which suggests that our sample behaves similarly to other samples on the simple question of the likelihood of talking. This result does not, of course, consider whom one talked to, or what one talked about. Consequently, one cannot infer from the probability of discussion anything about the structure of discussion.

Specifically, it is evident that most of the effects are in the expected direction. The older the respondent was, the more likely she reported not having discussed anything. Similarly, for individuals that were never married the propensity to talk is lower than for married people. The effect of gender on the likelihood of talking 
TABLE 4: Determinants of Talking About Important Matters

\begin{tabular}{lrc}
\hline & Beta & Standard Error \\
\hline Have you talked about important matters & & \\
Divorced/separated or widowed & .268 & $(.297)$ \\
Never married & -.631 & $(.366)$ \\
Race & .577 & $(.277)^{*}$ \\
Age & -1.194 & $(.453)^{* *}$ \\
Children & -.046 & $(.28)$ \\
Political opinion & -.278 & $(.242)$ \\
Gender & -.1 .425 & $(.744)$ \\
Working part-time/student & .211 & $(.39)$ \\
Notworking & .168 & $(.307)$ \\
Education & .992 & $(.157)^{* *}$ \\
Women ${ }^{*}$ Age & .530 & $(.265)^{*}$ \\
Constant & 3.074 & $(1.339)^{*}$ \\
$\mathrm{R}^{2}$ & & \\
(Observations $=596)$ & .11 & \\
\hline$*$ p $<.005 * * \mathrm{p}<.001$. & & \\
\hline
\end{tabular}

is rather interesting. Females are less likely to report talking about important matters in the last 6 months than are males. However, the interaction effect of gender and age is statistically significant. Consequently, one can infer that older women are more likely to report having discussed important matters than younger females. Finally, educated individuals are also more likely to have talked about something. In fact, the impact of education is extremely strong - holding all the other factors constant, having at least some college education increases the odds of talking with someone by a factor of almost 2.7 , compared to individuals that have just completed high school. Likewise, race plays an important role, the odds for white individuals to report talking about something in the last 6 months are $78 \%$ higher than for non-white. Finally, not all the predictors in the analysis were significant. In this analysis, neither employment status, having a political attitudes, or having children in the household are associated with the likelihood of talking about matters, important or not, in the past six months.

\section{Who Talks with Whom about What?}

Table 5 reports results of the cross-tabulation of topics and alters, by frequency, and row and column percentage (cells that are in bold represent percentages higher than their cross row and column marginals). ${ }^{8}$ From simple inspection of Table 5, one can reject the idea that alters and topics are independent $\left(x^{2}=35.98, p=0.055\right)$. It follows that the type of important matters that individuals reported talking about 
depends on who they talked with. Subsequently, we refer to this association as "roletopic" dependency. From Table 1, recall that the most common topic of conversation is money and household finances (money and house). Here we see that it is closely associated with talking to one's spouse. When partners are not talking about money, they talk about health. One-third of the conversations about life and health are between spouses, conversations with relatives are more likely to be about relationships than about anything else, and so on. It follows that the type of important matters that individuals reported talking about depends on whom they talked with. Which topic domains engage which alters in conversation is therefore a relevant question.

We answer this question by examining separately the patterning of topic domains and roles for men and women. Calculation of the $x^{2}$ residuals provides a measure of the contribution of each topic domain to the overall $\mathrm{x}^{2}$. Figure $\mathrm{l}$ (panels a-d) reports the difference between the residuals of men and women, for each alter. A negative value indicates a topic domain that was mostly talked about by women in their conversation with the reported alter, while positive values highlight men's conversation preferences.

Focusing first on the overall patterns for each relationship type, Figure 1 (panels a-d) show that talking with spouse, friend, and acquaintance evidence significant asymmetries in conversation flow, i.e., the topic domains engage different alters depending on gender. In contrast, with all the residuals very close to 0 , talking with other relatives appears to have the least differentiating patterning controlling for gender. Consequently, men and women (in our sample) talk with their relatives about the same important things, whatever they might be. More striking asymmetries emerge when one shifts focus to specific topic domains, for example, relationship. Figure la shows that married women (try to) talk about relationships with their husbands while their husbands ${ }^{9}$ talk about relationships with their friends. Similarly, married men report (monologue?) conversations about ideological issues with their wives, the latter whom report talking about ideological issues with their acquaintances.

In order to assess the statistical significance of these patterns, we can decompose Table 5 following Agresti (1990) by calculating a simple likelihood ratio. Here the numerator is the maximum likelihood when $\mathrm{H}_{0}$ is true, i.e., when the two factors are independent, while the denominator is the maximum likelihood under the alternative hypothesis, i.e., that the two factors are not independent. $\mathrm{G}^{2}$ is the likelihood ratio $\mathrm{x}^{2}$. The larger the value of $\mathrm{G}^{2}$ the more evidence we have that there is a dependence between the two variables. Thus, we use $\mathrm{G}^{2}$ to decompose the statistical dependency of topic domains and roles, separately by gender. Results are presented in Table 6.

Overall, for males we fail to reject the hypothesis of independence between topics of conversation and alter. By itself this is an interesting result which suggests that males are less differentiated than females. ${ }^{10}$ Still, even for males, there are substantive elements in play. Note that the $\mathrm{G}^{2}$ for spouse/friend accounts for almost 
Conversation Topics and Network Structure / 545

\section{FIGURE 1: Conversation Asymmetries}

Panel a: Conversation Asymmetries for Talking with Spouse

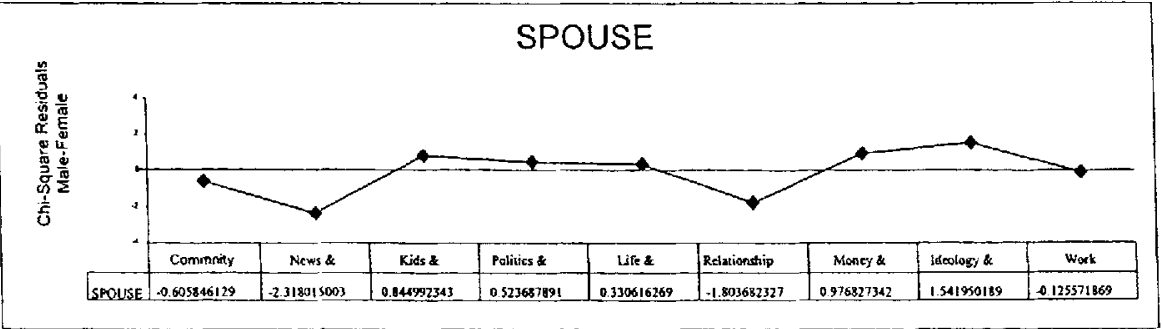

Panel b: Conversation Asymmetries for Talking with Friend

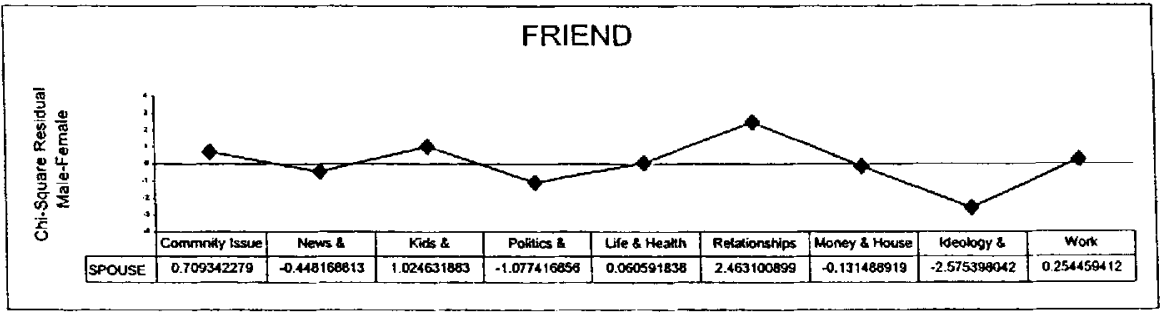

Panel c: Conversation Asymmetries for Talking with Other Relative

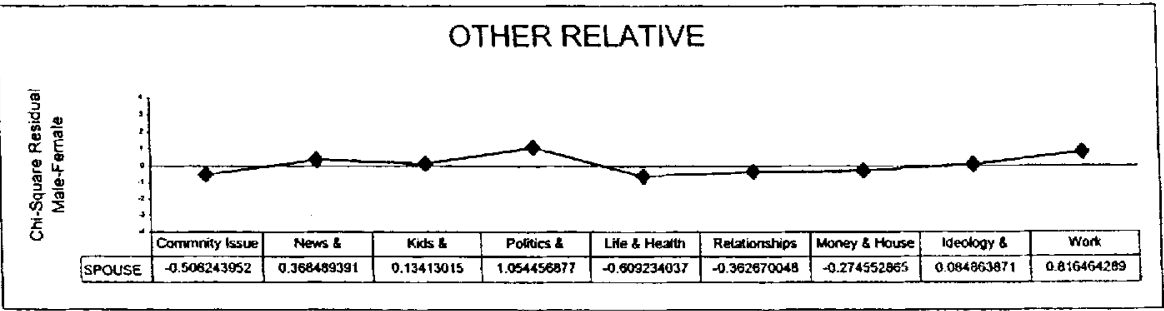

Panel d: Conversation Asymmetries for Talking with Acquaintance

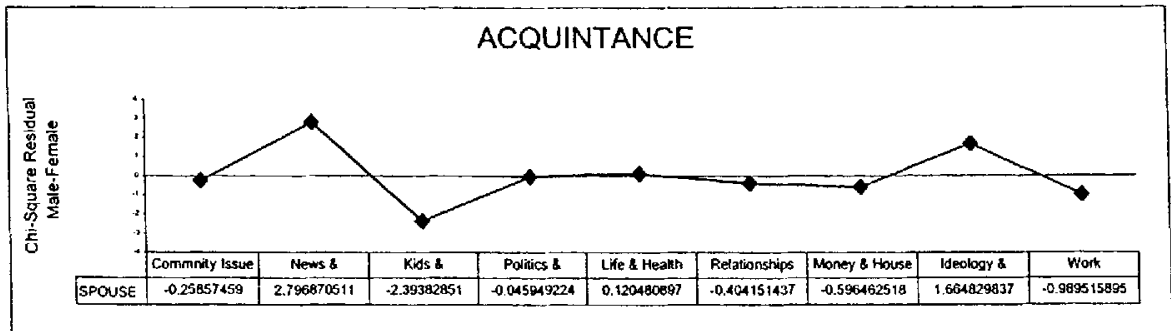


546 / Social Forces 83:2, December 2004

TABLE 5: Role-Topic Domain Dependency

\begin{tabular}{|c|c|c|c|c|c|}
\hline & Spouse & Friend & Other Relative & Acquaintance & Total \\
\hline \multicolumn{6}{|l|}{ Conversation Domain } \\
\hline \multirow[t]{3}{*}{ Community } & 12 & 23 & 6 & 19 & 60 \\
\hline & 20 & 38.3 & 10 & 31.7 & 100 \\
\hline & 8.3 & 12.2 & 9.7 & 17.6 & 11.9 \\
\hline \multirow[t]{3}{*}{ News and economy } & 10 & 12 & 2 & 9 & 33 \\
\hline & 30.3 & 36.4 & 6.1 & 27.3 & 100 \\
\hline & 6.9 & 6.4 & 3.2 & 8.3 & 6.6 \\
\hline \multirow[t]{3}{*}{ Kids and education } & 20 & 13 & 6 & 11 & 50 \\
\hline & 40 & 26 & 12 & 22 & 100 \\
\hline & 13.8 & 6.9 & 9.7 & 10.2 & 9.9 \\
\hline \multirow[t]{3}{*}{ Politics and election } & 14 & 24 & 6 & 13 & 57 \\
\hline & 24.6 & 42.1 & 10.5 & 22.8 & 100 \\
\hline & 9.7 & 12.8 & 9.68 & 12.0 & 11.3 \\
\hline \multirow[t]{3}{*}{ Life and health } & 21 & 20 & 9 & 12 & 62 \\
\hline & 33.9 & 32.3 & 14.5 & 19.4 & 100 \\
\hline & 14.5 & 10.6 & 14.5 & 11.1 & 12.3 \\
\hline \multirow[t]{3}{*}{ Relationships } & 15 & 20 & 11 & 4 & 50 \\
\hline & 30 & 40 & 22 & 8 & 100 \\
\hline & 10.3 & 10.6 & 17.7 & 3.7 & 9.9 \\
\hline \multirow[t]{3}{*}{ Money and house } & 32 & 23 & 9 & 16 & 80 \\
\hline & 40 & 28.8 & 11.2 & 20 & 100 \\
\hline & 22.1 & 12.2 & 14.5 & 14.8 & 15.9 \\
\hline \multirow[t]{3}{*}{ Ideology and religion } & 10 & 30 & 9 & 10 & 59 \\
\hline & 16.9 & 50.9 & 15.3 & 16.9 & 100 \\
\hline & 6.9 & 15.9 & 14.5 & 9.3 & 11.6 \\
\hline \multirow[t]{3}{*}{ Work } & 11 & 23 & 4 & 14 & 52 \\
\hline & 21.1 & 44.2 & 7.7 & 26.9 & 100 \\
\hline & 7.6 & 12.2 & 6.4 & 12.9 & 10.3 \\
\hline \multirow[t]{3}{*}{ Total } & 145 & 188 & 62 & 108 & 503 \\
\hline & 28.8 & 37.4 & 12.3 & 21.5 & 100 \\
\hline & 100 & 100 & 100 & 100 & 100 \\
\hline
\end{tabular}

Note: $\mathrm{N}$, row percent, column percent

$50 \%$ of the total $\mathrm{G}^{2}$ indicating a substantive, if not statistical, dependence of some topics to alters for males. Table 6 also suggests different behavior for married males and females. Specifically, married women talk about different important matters depending on whether they are talking with their husbands or with their friends. Husbands, for the most part, are indifferent with respect to conversation topic between these two alter sets. In marriages, asymmetries in conversation are apparent 
TABLE 6: Role-Topic Domain Dependency by Gender

\begin{tabular}{|c|c|c|c|c|}
\hline & $\begin{array}{l}\text { Spouse } \\
\text { vs. } \\
\text { Friend }\end{array}$ & $\begin{array}{c}\text { Spouse + Friend } \\
\text { vs. } \\
\text { Other Relative }\end{array}$ & $\begin{array}{c}\text { Spouse }+ \text { Friend }+ \\
\text { Other Relative } \\
\text { vs. } \\
\text { Acquaintance }\end{array}$ & Total \\
\hline Males & $\begin{array}{l}\mathrm{G}^{2}=12.50 \\
(\mathrm{p}=.13)\end{array}$ & $\begin{array}{l}G^{2}=1.53 \\
(p=.992)\end{array}$ & $\begin{array}{l}\mathrm{G}^{2}=12.03 \\
(\mathrm{p}=.15)\end{array}$ & $\begin{array}{l}\mathrm{G}^{2}=26.56 \\
(\mathrm{p}=.35)\end{array}$ \\
\hline Females & $\begin{array}{l}G^{2}=16.42 \\
(p=.037)^{\star}\end{array}$ & $\begin{array}{l}\mathrm{G}^{2}=5.28 \\
(p=.728)\end{array}$ & $\begin{array}{l}\mathrm{G}^{2}=11.02 \\
(\mathrm{p}=.201)\end{array}$ & $\begin{array}{l}\mathrm{G}^{2}=32.71 \\
(\mathrm{p}=.11)\end{array}$ \\
\hline
\end{tabular}

across three domains: community issues, news and economy, and relationships. Here, married women report talking about these important matters with their husbands. Husbands, on the other hand, do not report talking about these matters with their wives. ${ }^{11}$

These findings may provide insight into the dynamics of romantic relationships, but here we consider only the methodologically relevant issue which is that if we ask individuals with whom they talked about different topics in the last six months, we would generate different networks because their characteristics (e.g., married or not) determine what they consider important and therefore, given role dependency on topic (and vice versa), who they report talking to. Consequently, it is possible that most of the differences observed in previous work on the structure of male and female ego networks are an artifact of dependencies similar to those observed here. Subsequently, we consider the macro-structure of topics, attributes, and roles using correspondence analysis, a strategy that allows us to consider multiple dependencies simultaneously. Before this, though, it is important to learn more about (and locate in social space) the silent individuals.

\section{Who DOESN't TALK - AND WHY?}

As noted above, $20 \%$ of the respondents reported not talking about anything important with anyone. It is possible that nothing important happened to them, but on closer examination of the topics people did report as important matters for conversation, including but not limited to, children, gun control, my ex-wife running away, neighborhood security, the cloning of the headless frog, remodeling my home, the medical care system, and money, it would seem that the phrasing of the question did not eliminate a priori those without something really important to discuss. In general the network literature has assumed that the silent individuals are socially isolated. This turns out to be incorrect. Recall that we asked those who reported no conversations why they did not have any, whether for lack of persons to talk to or topics to talk about; $44 \%$ of the silent people had no one to talk to, $56 \%$ had nothing to talk about. ${ }^{12}$ 
TABLE 7: Who Talks to No One: Characteristics of the Silent Individuals

N Fischer's Exact Test for Independence

$\mathrm{p}$

\begin{tabular}{lll}
\hline Attributes & & \\
Race & 148 & $.049^{*}$ \\
Gender & 152 & .323 \\
Employment status & 152 & .187 \\
Education level & 152 & .631 \\
Marital status & 151 & $.051^{*}$ \\
Political opinion & 105 & .221 \\
Having a child & 152 & .476 \\
Agc & 150 & .332
\end{tabular}

${ }^{*} \mathrm{p}<.005$

It is reasonable to define isolation as the absence of social ties. Consequently, one can expect that the individuals who reported not talking about anything because they had no one with whom to talk are more likely to be social isolates than the individuals that reported not talking because they had nothing important to say. We test this idea by considering the association of isolation and some key individual characteristics ${ }^{13}$ and report the results in Table 7.

With respect to isolation, race and marital status appear to be the only two relevant attributes. In particular, while white individuals predominantly reported not having topics to discuss (62\%), nonwhite respondents mostly reported not talking because they did not have people to talk with. This difference is statistically significant $(a=0.05 ; \mathrm{CI}, 0.183-0.152) .{ }^{14}$

Note that married individuals were more likely to be silent than isolates (66\%) while the reverse was true for divorced or widowed respondents. In other words, of those who did not talk, the married said they did not talk because they had nothing to talk about, and the divorced (or widowed) said they did not talk because they had no one to talk to. No difference was observed for never-married individuals. ${ }^{15}$ In our sample, almost $40 \%$ of the isolated individuals were divorced, while $23 \%$ were never married. Thus, among the silent individuals, a subgroup of nonwhite and not-married individuals can be identified. We consider this finding in more detail subsequently.

\section{The Macro-Structure of Conversation}

In order to explore the nature of the association between the symbolic network of roles, topics of conversation, and individuals' characteristics we represent the social structure of topic domains and alters' using multiple correspondence analysis (MCA). The results of this analysis are reported in Figure $2 .^{16}$ 


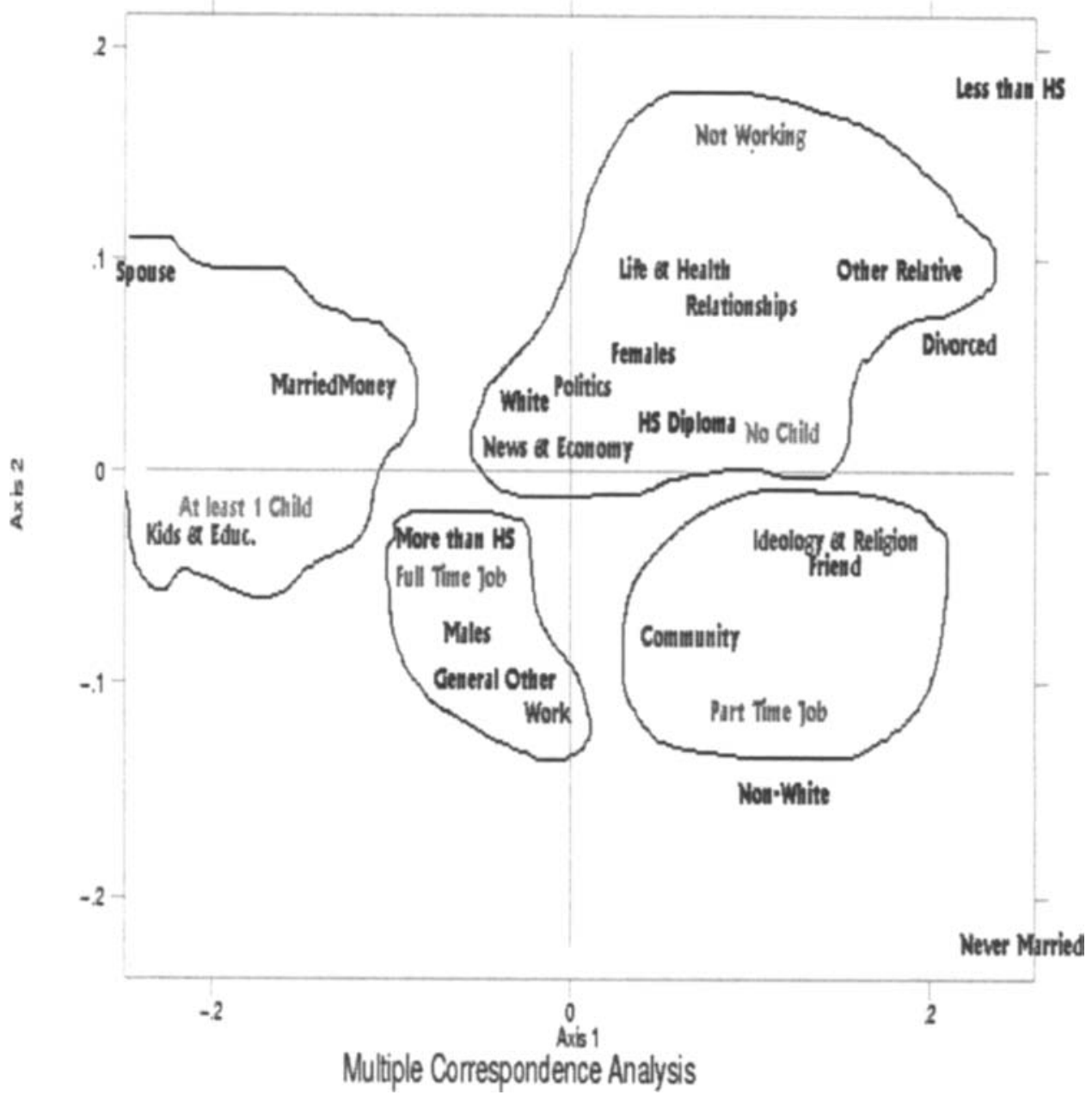

Elements close to other elements in the state space are similar in profile. Thus, for example, the cluster of attributes (male, full-time employment, college education) in the bottom left quadrant (cell 1,2$)$ indicates that they bunch together, in contrast to the attributes in the top right quadrant (cell 2,1) associated with being female, e.g., part-time work and high school education. Likewise, conversation topics that cluster together share similar profiles across the roles and attributes, whereas those more distant in the state space are different. Working our way through Figure 2, we can first observe that the four alter roles are located in 
separate quadrants. Starting from the 1st quadrant and working our way through the $2 \times 2$ matrix, indexing quadrants by row and column, we find, consequently: spouse $(1,1)$, other relative $(1,2)$, friend $(2,2)$ and acquaintance $(2,1)$. Consequently, with respect to the joint structuring of attributes and conversation domains, each alter role is different from the others. Whom one discusses important matters with is jointly shaped by the matter, the role, and the attributes of ego (and alter).

Focusing first only on the overlap of topic and role (the dependency issue considered previously, but here as conditioned by the macro-level distribution of attributes) we can observe, for example that friends occupy the same quadrant as ideology and religion and community. In contrast, spouse occupies the same quadrant as money and finance. These associations are represented in stylized form in Figure 3a, which simply abstracts data in Figure 2 to reveal the main structure. From Figure $3 \mathrm{a}$ it is easy to see that the rows reflect different positions with respect to kinship. Kin conversation networks (spouse and relative) are in row 1, whereas nonkin conversation networks (friends and acquaintances) are in row 2. Not surprisingly, instrumental - column 1 - conversation domains (work, money, etc.) are distinguished from affective, intellectual, and abstract rhetorical conversation domains in column 2. Note that one can talk about the news with anyone - or posed alternatively the news as conversation topic can support any dyadic pair. In that sense it serves the generic function of small talk, conversation that is not revelatory of the personality and so can match to any available role alter.

Further decomposing Figure 2, Figure $3 \mathrm{~b}$ locates in stylized space the attribute structure of the overall graph. Following the same convention for working through each quadrant, we observe a series of oppositions. Males, those who are working, and those with college education are in cell $(2,1)$; whereas females, the unemployed, and those with less than a high school education are in cell $(1,2)$. Race and marital status crosscut the SES divide.

Returning to Figure 2 (the correspondence analysis), recall that the horizontal axis separates kin conversation networks from nonkin networks, while the vertical dimension separates instrumental from affective topics. From previous research we might expect that females would be located in the state space closer to kin and affective discussion contents than males, who are embedded in instrumental and nonkin networks and conversations. But here we show that this is as likely a structural feature of the organization of role-topic dependencies as it is a reflection of underlying differences in network composition.

This is confirmed by the fact that the role-alter "spouse" (for the first dimension) and employment status (for the second dimension) accounts for almost $25 \%$ of the variance in each dimension respectively. The positioning of profiles suggests that while male's talk mostly with those outside the family, females do the reverse. From a different perspective, inside the family network, women participate in more heterogeneous conversation domains, as it is evident by their association with politics 


\section{FIGURE 3}

3A - Stylized Role-Topic Clustering

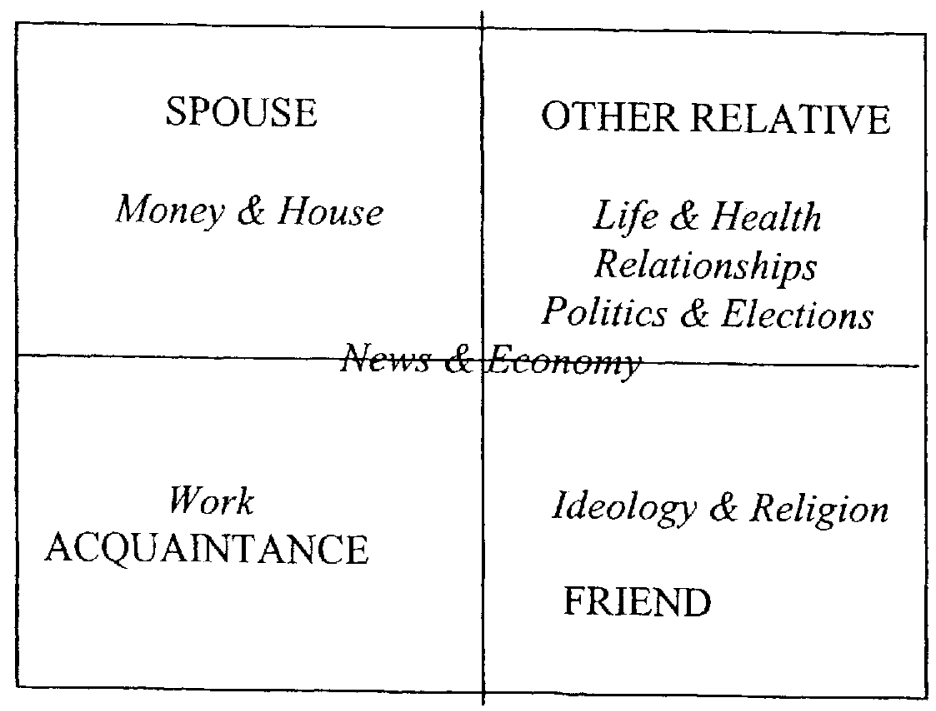

3B - Stylized Clustering of Individual Characteristics

\begin{tabular}{|l|r|}
\hline Married & Less than HS \\
& Not Working \\
& Female \\
\hline Some College & Non-White \\
Working & \\
\hline
\end{tabular}




\section{2 / Social Forces 83:2, December 2004}

and elections and life and relationships, for example. On the other hand, men appear to be embedded in conversation ties mostly related with their work.

Finally, we consider those individuals who were silent. While they cannot be included in the MCA (they talked to no one), it is worth noting that silent and isolated individuals - those who reported not talking about anything important in the last 6 months - are with respect to their social structural characteristics located in the bottom corner of the 4 th quadrant, closely associated with never being married, having a part-time job, and being nonwhite.

\section{Discussion}

For more than a generation, social scientists have used the GSS social network instrument to measure the social worlds of individuals. Oddly, few people wondered what the instrument measured, and even more oddly, no one bothered to find out what kinds of topics were considered important enough to warrant reporting. When individuals reported not talking with anyone, the social science community interpreted this as a striking fact of social isolation, giving rise to the idea that in the U.S., large numbers of people were without associates and friends, isolated, anomic, and completely disembodied.

Likewise, social scientists routinely considered the relationship between network characteristics and substantive outcomes of relative significance, for example, job attainment as unproblematic. The mechanism linking conversations to the attainment of individual ends was never clearly specified, but it seemed reasonable to presume that if people talked about something important they would also share news and information about other important things. So the instrument appeared to be a useful proxy, standing in an equivalence relation, for something that could assist achievement of individual ends. But is this really the case?

In this article we consider the extent to which one might have confidence in the GSS name generator, and the extent to which one might have confidence using the instrument across contexts, and across roles. First, we show that half of the people who report not talking about anything do not report being isolated. They simply do not have something they think is important to talk about. The other $50 \%$ may want to talk about the cloning of the headless frog, a shooting on the highway, the state of the economy, the failure of the space program, the moral decay of our political leaders, their neighbor's apple tree, or the ease of obtaining pornography on the Internet, but they do not have anyone to talk to. They are the isolated, and not surprisingly, they are those who lost partners and are without jobs. Perhaps more interesting, they are also nonwhite. So we need to reevaluate our assessment of the proportion isolated, and consequently the sociological meaning of isolation, in the U.S. context.

Second, many of the matters people consider important enough to report having conversation about often bear only the vaguest and most tenuous relationship to 
the achievement of instrumental ends. It is always possible that talking about a headless frog may get you a job, but the pathway is certainly not clear. Likewise, talking about what school to send the kids to may help build attachment to community, but it is certainly not clear how this would come about. Since the topics of conversation are so often trivial news events, one should be cautious inferring that the conversation networks that arise from such discussions are of substantive importance. These are the simplest points.

More important, and more interesting, is the strong association we observe between role and topics, for some dyadic pairs. The finding that wives talk about relationships with their husbands while husbands talk about relationships with their friends provides perhaps the most graphic example. Why should one care about such dependencies? Imagine a world in which women define as important conversations about relationships and men define as important conversations about news. In this case, we would observe, using a GSS-style instrument, that women talk to kin and men talk to others. We would therefore observe that the networks of men and women differ with respect to proportion kin, heterogeneity, and density of the ego-network, to select just some common measures. Men would look as if they were embedded in weak-tie networks, whereas women would, overall, appear to be embedded in strong-tie networks. Indeed, this is what Gwen Moore suggests in her analysis of the 1985 GSS data (1990). Now, because males tend to have better jobs than women, one would be tempted to observe that the association between jobs and networks was (in some sense) real. But the association between jobs (for example) and network characteristics is likely, given the topic-role dependency we observe, to be an artifact of the asymmetry in the structuring of topics by alters. A far less problematic approach would be to break the important questions name generator down into the set of constituent domains that organize the structuring of discussion in the U.S.

Needless to say, in societies where different cultural norms govern the relationship between alters and topics (e.g., China) comparison of observed structures to the U.S. pattern is likely to be seriously misleading. (Blau, Ruan \& Ardelt 1991). Just considering the Chinese case, for example, Blau and colleagues report that $16 \%$ of U.S. conversations are with coworkers, whereas $35 \%$ in China are with coworkers; likewise relatively large differences can be observed for kin (39\% in China, $53 \%$ in the U.S.). If, as we suggest, there is evidence for role-topic dependency, this result could easily arise from the dependency, rather than different network opportunities, as previously imagined.

The structure of the role-topic (and attribute) dependency is revealed most clearly by the multiple correspondence analysis in which we observe marked patterning of alters, attributes, and topics at the macro-level - a pattern which is strongly conditioned by employment status and kinship relations. Whether such macro-level patterning is common across contexts is unknown. The fact that the silent and isolated individuals in our sample are mostly non-white suggests that in social formations less stratified by race, different patterns should emerge. 
Consequently, one would have to be hesitant to make direct cross-national comparison at the micro-level of individual networks, since they likely reflect underlying distributions of opportunities.

What should be done? It is clear that the GSS name generator captures something and it captures it with consistency. The evidence for this is that the predictors of talking in our sample are the same, more or less, as reported across a diverse literature. There is clearly much to be learned from an orienting question about important matters, whatever the matters turn out to be that are important. But for studies which seek to compare impacts of network structure on outcomes, focusing on key attributes such as gender and marital status (for example), this article suggests that researchers would benefit from focusing on specific conversation domains, and comparing networks arising from those domains, given the strong overlap between persons, roles, and topics of conversation. Likewise, for individuals interested in cross-national comparison, attention to the structure of conversation topic-role dependencies seems equally critical, for it is reasonable to think that the patterning of these dependencies at the macro-level gives rise to much of the significant variation one often observes at the micro-level.

\section{Notes}

1. The wording of the name generator has been a matter of concern from the beginning. In the original version, "personal" stood in place of "important." Ruan (1998) reports that the original question was changed to the current one because of the narrow interpretation that some people gave to "personal matters."

2. That is, perhaps like econometrics and sausage, one should ignore the ingredients if it tastes fine. Note also that different name generators have also been tested sequentially and the alters so obtained compared to each other (Van der Poel 1993). The results of this work suggest that groups of alters do differ when switching from one generator to another. But the mnemonic bias introduced by the sequentiality of the research design is problematic as alters may come to mind in a later generator because they were elicited by a previous question (Straits 2000).

3. Of course, these seemingly trivial topics may really be instantiations of important topics, thus considered in order, reflections on the hegemony of appearance in modern capitalist society (the haircut), the veracity of the Putnam thesis on associational life in the U.S. (the neighbors' lawn), and concern over the hyperrationalization of modern society, and the concomitant breakdown of customary norms for governing interactions (the traffic light), etc. We are not actually interested in whether the specific items are "important" in an objective sense, whatever that may be, but instead in the patterning of matters across alters.

4. The North Carolina Poll is a representative study of North Carolinians. The sample is stratified by county of residence. Across strata, 2,933 telephone numbers were selected. A number was dropped if (1) it was proved to be nonworking $(n=530)$; ) the number 


\section{Conversation Topics and Network Structure / 555}

was nonresidential ( $n=212$ or there was no eligible respondent living at that number ( $n=76)$; (2) the interview was refused $(n=493)$ or terminated $(n=144)$; (3) there was no answer $(N=311)$ or a busy signal, answering machine, or fax after three attempts were made at least one hour apart $(n=396)$. Consequently, 771 interviews were completed, yielding a response rate of roughly $62.5 \%$ when interviews terminated after the network protocol are included. It is hard to interpret potential selection bias arising from (3) above. Clearly, for these analyses, one could imagine that the design selects for people without large networks, since they would be more likely to be engaged in long telephone conversations. Of course, these people could also be terribly lonely internet surfers, trapped in long distant chat rooms. We believe any such effects are minimal.

5. In pretests we discovered that the content of the important matters reported was strongly influenced by prior questions on the survey. In fact, when education was the initial topic of the survey, more than $60 \%$ of the respondents reported that the topic they last talked about was education. Consequently, these questions were the first asked in the survey.

6. Independent coders assisted in the aggregation of responses to these domains. Intercoder reliability was high, well over $90 \%$. Obviously, the choice of nine categories (versus 8,10 , etc) is more difficult. By chance, the distribution across domains is roughly equivalent, which is useful statistically and provides some support for the idea that we have in fact arrived at a reasonable scheme. The heterogeneity of responses within domains varies somewhat. The domain, News and Economy, for example, contains the following kinds of answers: Economy of the country, Stock market, Political things such as the stock market, daily news, economical development in the Third World, stock market fall, economy in North Carolina livestock, situation in Middle East (oil), and so on. Specific assignments of topics to domains are available on request.

7. The specific equation is:

$$
a_{k}=\frac{Q}{Q-1} \cdot\left(E V_{k} \cdot \frac{1}{Q}\right)^{2}
$$

where a $k$ is the adjusted inertia of dimension $k$.

8. The marginal frequencies reported in Table 5 are slightly different than those reported in Figure 1, since some respondents specified a topic but not an alter $(n=3)$ and some other specified an alter but not a topic $(n=90)$.

9. Here, "spouse" also includes domestic partners.

10. In Suicide, Durkheim argues that women are less "developed" than men because they evidence less social differentiation. It is amusing, then, to observe that if one used the same logic (though not recommended) one finds evidence of the obverse.

11. These asymmetries could arise because men and women code the same conversation differently, for example one could imagine that men could code a conversation about autonomy as a conversation about money and finances, whereas a woman could code it as a conversation about relationships.

12. Unfortunately we did not think to ask people who had nobody to talk to what they might have talked about if they had somebody, and vice-versa. 
13. Given the small sample size, we used the Fischer Exact Test (FET), given that "under the null hypothesis of independence, an exact distribution that is free on any unknown parameters results from conditioning on the marginal frequencies in both margins" (Agresti 1990:60). The equation for FET is:

$$
F E T=\frac{\prod_{i} n_{i !} ! \prod_{j} n_{. j}}{n ! \prod \prod n_{i j} !} .
$$

14. Let Pnw and Pw be, respectively, the proportion of isolate non-white and white individuals. The standard error of the difference of these two proportions is given by,

$$
S E\left(p_{n w}-p_{w}\right)=\sqrt{\frac{p_{w} \cdot q_{w}}{n_{w}}+\frac{p_{n w} \cdot q_{n w}}{n_{n w}}},
$$

where $q=1-p$. The confidence interval is obtained using Yates correction for normality:

$$
-\frac{1}{2} \cdot\left(\frac{1}{n_{n w}}+\frac{1}{n_{w}}\right) .
$$

15. We tested the hypothesis that the likelihood of being an isolate was arrayed on marital status, with never-married individuals more likely to be isolated and married ones less likely to identify as such. Using Bartholomew's test we find that the observed order departs significantly from expectations $\left(\mathrm{x}^{2}=5.8565>5.098=\mathrm{C}_{0.05,0.49}\right)$. Here, we use the following equation,

$$
\overline{\chi^{2}}=\frac{1}{\bar{P} \cdot Q} \sum_{i} n_{i} \cdot\left(p^{\prime}-\bar{P}^{2},\right.
$$

where, the revised proportions for never-married and divorced individuals are given by their weighted average,

$$
p^{\prime}=\frac{30 \cdot 0.5+47 \cdot 0.553}{30+47} .
$$

For three groups, then, C is constructed following (Fleiss, 1981); viz:

$$
c=\sqrt{\frac{n_{1} \cdot n_{2}}{\left(n_{1}+n_{2}\right)\left(n_{2}+n_{3}\right)}}=0.49 .
$$

16. The total inertia of the matrix suggests a high concentration of the profiles toward the center of the space. The contraction for the horizontal dimension is (roughly) a factor of 8 , for the vertical dimension (roughly) a factor of 13 .

\section{References}

Agresti, Alan. 1990. Categorical Data Analysis. Wiley.

Alex-Assensoh, Yvette. 1997. "Race, Concentrated Poverty, Social Isolation, and Political Behavior." Urban Affairs Review 33:209-27. 
Bailey, S., and Peter V. Marsden. 1999. "Interpretation and Interview Context: Examining the General Social Survey Name Generator Using Cognitive Methods." Social Networks 21:287309.

Blau, Peter M., Danching Ruan, and Monika Ardelt. 1991. "Interpersonal Choice and Networks in China." Social Forces 69:1037-62.

Campbell, Karen E., and Barrett A. Lee. 1991. "Name Generators in Survey of Personal Networks." Social Networks 13:203-21

Durkheim, Emile. 1951. Suicide: A Study in Sociology. Free Press.

Fischer, Claude S. 1982. To Dwell among Friends: Personal Networks in Town and City. University of Chicago Press.

Fleiss, Joseph. 1981. Statistical Method for Rates and Proportions. 2d ed. Wiley.

Granovetter, Mark. 1973. "The Strength of Weak Ties." American Journal of Sociology 78:136080.

Greenacre, Michael, and Jorg Blasius (eds.). 1994. Correspondence Analysis in the Social Sciences. Academic Press.

Guest, Avery M., and Susan K. Wierzbicki. 1999. "Social Ties at The Neighborhood Level: Two Decades of GSS Evidence." Urban Affairs Review 35:92-111.

Marsden, Peter V. 1987. "Core Discussion Networks of Americans." American Sociological Review 52:122-31.

Moore, Gwen. 1990. "Structural Determinants of Men's and Women's Personal Networks." American Sociological Review 55:726-35.

Rankin, Bruce H., and James M. Quane. 2000. "Neighborhood Poverty and the Social Isolation of Inner-City African American Families." Social Forces 79:139-64.

Ruan, Danching. 1998. "The Content of the General Social Survey Discussion Networks: An Exploration of the General Social Survey Discussion Name Generator in a Chinese Context." Social Networks 20:247-64.

Smith, Tom W., and Kaddin Heaney. 1995. "Who, What, When, Where, and Why: An Analysis of Usage of the General Social Survey, 1972-1993." National Opinion Research Center. University of Chicago.

Straits, Bruce C. 2000. "Ego's Important Discussants or Significant People: And Experiment in Varying the Wording of Personal Network Name Generators." Social Networks 22:123-40.

Van der Poel, Mart G.M. 1993. “Delineating Personal Support Networks.” Social Networks 15:4970 . 